\title{
Antioxidant Properties of Green Synthesized Silver Nanoparticles from Sargassum wightii
}

\author{
Jayaprakash Ponmani ${ }^{1}$, Sivakumari Kanakarajan ${ }^{2 *}$, Rajesh Selvaraj ${ }^{1}$, Ashok Kamalanathan ${ }^{1}$ \\ ${ }^{1}$ Department of Zoology, Presidency College, Chennai - 600005, Tamilnadu, India \\ ${ }^{2}$ Associate Professor, Department of Zoology, Presidency College, Chennai - 600005, Tamilnadu, India
}

DOI: $10.36348 /$ simps.2020.v06i08.001

| Received: 02.08.2020 | Accepted: 09.08.2020 | Published: 14.08.2020

*Corresponding author: Dr. Sivakumari Kanakarajan

\section{Abstract}

Natural antioxidants and their association with health benefits have gained unprecedented attention in recent years. They have multiple functions in biological systems and mainly defense against oxidation that produce free radicals in food, chemicals and in living systems. During the past decades, synthesized nanoparticles from marine organisms and many of these substances have been demonstrated to posses exciting biological activities. With this background, S. wightii and its AgNPs were analyzed for their antioxidant properties. Green synthesis of silver nanoparticles was carried out using the aqueous extract of $S$. wightii. The aqueous extract of $S$. wightii showed significant potential for the quick reduction of silver ions. The antioxidant properties of green synthesized AgNPs was carried out and it showed significant activity when compared with standard. The present work of green synthesis of silver nanoparticles using S. wightii appears to be cost effective, eco-friendly, and an alternative to conventional method of synthesis. In the present study, the aqueous extract and its synthesized AgNPs showed high antioxidant activity to the best of our knowledge. Hence, green synthesized AgNPs of $S$. wightii can be used as a potential therapeutic drug for various diseases due to its bioactive properties.

Keywords: DPPH, Super Oxide Anion, Metal Chelating, Nitric Oxide, S. wightii, AgNPs.

Copyright @ 2020: This is an open-access article distributed under the terms of the Creative Commons Attribution license which permits unrestricted use, distribution, and reproduction in any medium for non-commercial use (NonCommercial, or CC-BY-NC) provided the original author and source are credited.

\section{INTRODUCTION}

The field of nanotechnology is one of the most active areas of research in modern materials science. Nanotechnology is emerging as a cutting edge technology interdisciplinary with biology, chemistry and material science [1]. Nano-medicine is an emerging field expanding rapidly because of the development and incorporation of new nano composites into a range of products and technologies [2]. In recent years, the application of nanoparticles (NPs) in medicine has increased and expanded to the fields of molecular imaging [3], drug delivery [4], diagnosis and treatment of cardiovascular diseases [5], wound healing [6], anticancer [7, 8] and development of materials and medical devices with antimicrobial properties [9]. New applications of nanoparticles and nanomaterials are emerging rapidly in biomedical sciences $[2,10]$.

Seaweeds contain some valuable nutrients as well as pharmacologically active substances, and nowa-days there is a lot of interest in seaweed meals, functional foods and nutraceuticals for human consumption [11]. Sargassum, one of the marine macro algae belonging to the class Phaeophyceae, is widely distributed in tropical and temperate oceans; it is large, cost-effective, important and ecologically dominant brown algae present in much of the tropics. It is found to be the most diverse genus among Phaeophyta in India and is represented by 38 species [12].

Sargassum wightii is one of the important species belonging to the genus Sargassum and a wide range of bioactive properties have been reported from this species [13]. Since Sargassum wightii is available in large quantities, it appears to be the most suitable raw material for commercial exploitation. Based on the literature, in the present study, the antioxidant activity was assessed by DPPH, super oxide anion radical scavenging activity, metal chelating activity and nitric oxide radical scavenging activity. 


\section{Materials AND MethodS}

\section{Green Synthesis of Silver Nanoparticles (AgNPs) from Sargassum wightii}

Green synthesis of AgNPs was carried out by the method of Song and Kim [14]. Best AgNPs synthesis was observed best in the aqueous extract of $S$. wightii, while other solvents extracts showed poor synthesis of AgNPs, and this may due poor solubility of solvent extracts and silver nitrate dissolved in water as reported by Jayaprakash et al., [15]. Based on the results, antioxidant potential of aqueous extract and its green synthesized AgNPs from $S$. wightii was evaluated.

\section{Evaluation of Antioxidant Potential DPPH Assay}

The antioxidant potential was determined by 2 , 2-diphenyl-1-picrylhydrazyl (DPPH) free radical scavenging activity by the modified method of McCune and Johns [16]. The reaction mixture $(3.0 \mathrm{ml})$ consisting of $1.0 \mathrm{ml} \mathrm{DPPH}$ in methanol, $1.0 \mathrm{ml}$ methanol and $1.0 \mathrm{ml}$ different concentrations of aqueous extract, synthesized AgNPs and standard BHT $(20,40,60,80$ and $100 \mu \mathrm{g} / \mathrm{ml})$ was incubated in dark for $10 \mathrm{~min}$., after which the absorbance was measured at $517 \mathrm{~nm}$ against blank. For control, $1.0 \mathrm{ml}$ of methanol was used in place of aqueous and synthesized AgNPs. Percentage of inhibition was calculated using the formula:

$$
\text { Inhibition }(\%)=\frac{\mathrm{A} 0-\mathrm{A} 1}{\mathrm{~A} 0} \times 100
$$

Where, A0 is the absorbance of control and A1 is the absorbance of sample.

\section{Super Oxide Anion Radical Scavenging Assay}

Super oxide anion radical scavenging activity was estimated according to the method of Jing and Zhao [17]. To $1.0 \mathrm{ml}$ of NBT solution, $1.0 \mathrm{ml}$ of NADH solution, $0.1 \mathrm{ml}$ of PMS solution and 20, 40, 60, 80 and $100 \mu \mathrm{g} / \mathrm{ml}$ of aqueous extract, synthesized AgNPs and standard ruitn were added together in their respective tubes and incubated at $25^{\circ} \mathrm{C}$ for $5 \mathrm{~min}$. After $5 \mathrm{~min}$. the absorbance was read at $560 \mathrm{~nm}$. The percentage of scavenging activity was calculated by the following formula:

$$
\text { Scavenging activity }(\%)=\frac{\mathrm{AC}-\mathrm{AS}}{\mathrm{AC}} \times 100
$$

Where, AC was the absorbance of the control (deionized water, instead of sample), and AS was the absorbance of the test sample mixed with reaction solution.

\section{Metal Chelating Assay}

Metal chelating activity was done according to the method of Soler-Rivas et al., [18]. Different concentrations $(20,40,60,80$ and $100 \mu \mathrm{g} / \mathrm{ml})$ of aqueous extract, synthesized AgNPs and standard EDTA were dissolved in DMSO. To this, $50 \mu \mathrm{l}$ of ferrous chloride solution and $200 \mu \mathrm{l}$ of ferrozine solution were added. The solutions were mixed thoroughly and incubated in dark at room temperature for $10 \mathrm{~min}$. The absorbance was read at $562 \mathrm{~nm}$. The percentage of metal chelating activity was calculated by the following formula:

$$
\text { Chelating rate }(\%)=\frac{\mathrm{A} 0-\mathrm{A} 1}{\mathrm{~A} 0} \times 100
$$

Where, A0 was the absorbance of the control (blank without extract) and A1 was the absorbance in the present of the extract. Then $\mathrm{IC}_{50}$ value was calculated from the formula on the graph.

\section{Nitric Oxide Radical Scavenging Assay}

Nitric oxide radical inhibition was estimated by Griess Illosvoy reaction method of Green et al. (1982) [19]. A volume of $0.5 \mathrm{ml}$ of sodium nitroprusside in phosphate buffered saline was mixed with $1.0 \mathrm{ml}$ of aqueous extract, AgNPs and standard BHT $(20,40,60,80$ and $100 \mu \mathrm{g} / \mathrm{ml})$ in their respective tubes and incubated at $25^{\circ} \mathrm{C}$ for $180 \mathrm{~min}$. The extract was mixed with an equal volume of freshly prepared Griess reagent. Control samples without the samples but with an equal volume of buffer were prepared in a similar manner as was done for the test samples. A volume of $150 \mu \mathrm{l}$ of the reaction mixture was transferred to a 96-well plate. The absorbance was measured at $546 \mathrm{~nm}$ using a SpectraMaxPlus UV-Vis microplate reader (Molecular Devices, GA, USA). BHT was used as the positive control. The percentage nitrite radical scavenging activity of the sample and BHT were calculated using the following formula:

Nitric oxide radical scavenging effect $(\%)=\frac{\mathrm{AC}-\mathrm{AS}}{\mathrm{AC}} \times 100$

Where, AC is the absorbance of control sample and AS is the absorbance of samples.

\section{Statistical Analysis}

The data with five replicates for antioxidant potential assays were subjected to statistical analysis and the mean value along with its respective standard error was calculated. The per cent change between control and experimental data were calculated. The data were analyzed statistically using Two Way Analysis of Variance (ANOVA). The data along with tables and graphs/bar diagrams are presented in appropriate places in the results section [20].

\section{ReSUlTS}

\section{Evaluation of Antioxidant Potential \\ DPPH Activity}

DPPH radical scavenging activity of aqueous extract and AgNPs of S.wightii and standard BHT are presented in Table-1. The per cent inhibition of DPPH 
activity in aqueous and AgNPs was directly proportional to the concentration of the samples. When compared, the inhibition was high in AgNPs than that of the aqueous extract; the values being from -10.66 to 49.38 in aqueous extract and from -20.65 to -64.83 in AgNPs. When compared with that of standard BHT, the per cent inhibition of DPPH in AgNPs was more or less similar to that of the standard. Statistical treatment of the data by two-way ANOVA revealed that all the values were significant at $5 \%$ level. The mean inhibitory concentration $\left(\mathrm{IC}_{50}\right)$ of aqueous extract, AgNPs and BHT was found to be $102.59 \mu \mathrm{g} / \mathrm{ml}, 59.67$ $\mu \mathrm{g} / \mathrm{ml}$ and $53.94 \mu \mathrm{g} / \mathrm{ml}$, respectively. The results clearly indicate that AgNPs have profound reducing activity against stable free radicals (Fig-1).

Table-1: DPPH radical scavenging activity of aqueous extract and AgNPs of S. wightii

\begin{tabular}{|l|l|l|l|}
\hline Concentration & Aqueous Extract & AgNPs & BHT \\
\hline Control & $100 \pm 0$ & $100 \pm 0$ & $100 \pm 0$ \\
\hline $20 \mu \mathrm{g} / \mathrm{ml}$ & $0.876 \pm 0.004^{*}$ & $0.965 \pm 0.003^{*}$ & $0.984 \pm 0.002^{*}$ \\
& $(-10.66)$ & $(-20.65)$ & $(-18.92)$ \\
\hline $40 \mu \mathrm{g} / \mathrm{ml}$ & $0.712 \pm 0.001^{*}$ & $0.866 \pm 0.002 *$ & $0.758 \pm 0.002^{*}$ \\
& $(-27.42)$ & $(-29.69)$ & $(-37.56)$ \\
\hline $60 \mu \mathrm{g} / \mathrm{ml}$ & $0.617 \pm 0.002^{*}$ & $0.641 \pm 0.001 *$ & $0.541 \pm 0.004^{*}$ \\
& $(-36.93)$ & $(-50.35)$ & $(-55.41)$ \\
\hline $80 \mu \mathrm{g} / \mathrm{ml}$ & $0.548 \pm 0.003^{*}$ & $0.492 \pm 0.001^{*}$ & $0.358 \pm 0.003^{*}$ \\
& $(-44.17)$ & $(-54.93)$ & $(-70.54)$ \\
\hline $100 \mu \mathrm{g} / \mathrm{ml}$ & $0.497 \pm 0.002^{*}$ & $0.384 \pm 0.004^{*}$ & $0.195 \pm 0.002^{*}$ \\
& $(-49.38)$ & $(-64.83)$ & $(-83.96)$ \\
\hline $\mathbf{I C}_{\mathbf{5 0}}(\boldsymbol{\mu g} / \mathrm{ml})$ & 102.59 & 59.67 & 53.94 \\
\hline
\end{tabular}

Values are mean \pm S.E. of five individual observations.

Values in parentheses are per cent change over control.

- Denotes per cent decrease over control.

$*$ Denotes that values are significant at $\mathrm{p}<0.05$.

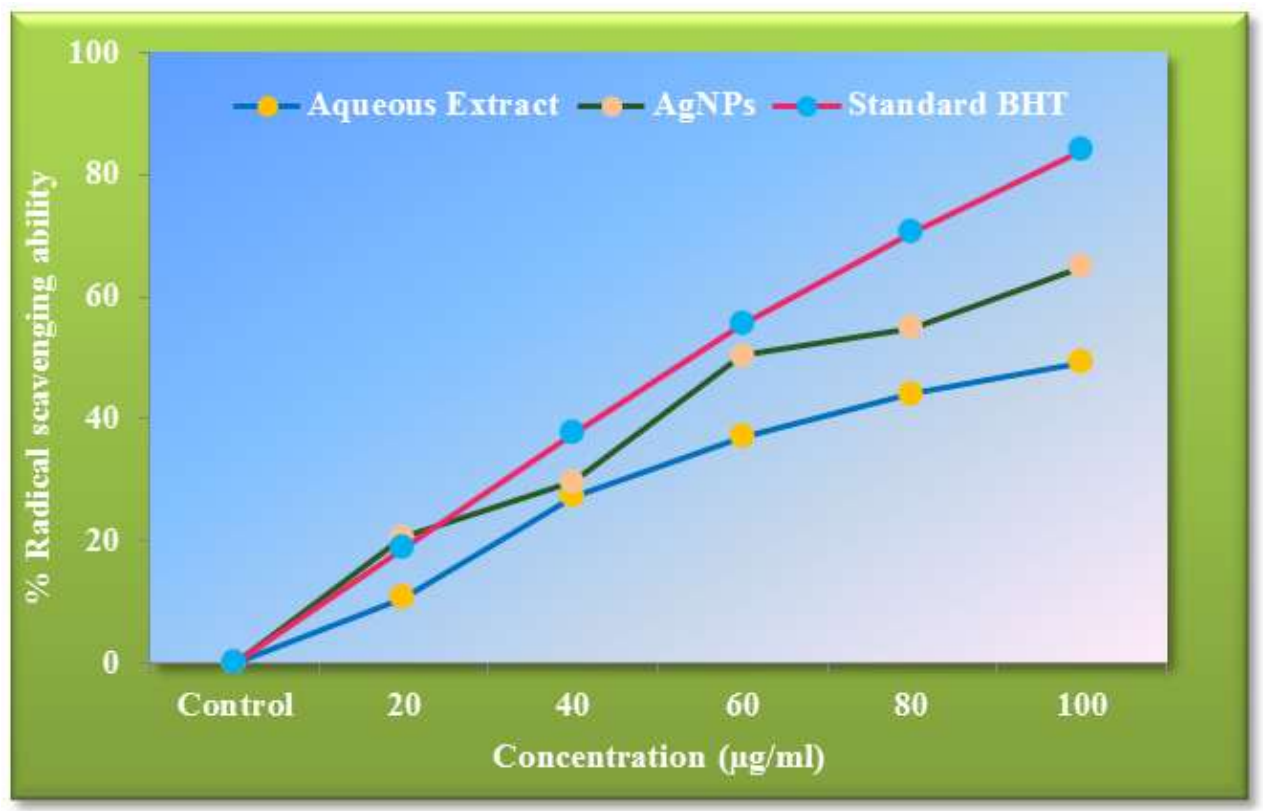

Fig-1: DPPH radical scavenging activity of aqueous extract and AgNPs of $S$. wightii

\section{Super Oxide Anion Radical Scavenging Activity}

Super oxide radical scavenging activity of aqueous extract and AgNPs of S. wightii depicted a per cent inhibition by SOD that was directly proportional to the concentration of the samples; the values being from - 7.30 to -59.27 in aqueous extract and from - 7.48 to 64.31 in AgNPs (Table-2). The per cent inhibition of SOD in AgNPs was more or less similar to that of the standard and the values were significantly different from each other at $5 \%$ level when analyzed by two-way ANOVA. The median inhibitory concentration $\left(\mathrm{IC}_{50}\right)$ of aqueous extract, AgNPs and rutin was found to be $82.59 \mu \mathrm{g} / \mathrm{ml}, \quad 59.08 \mu \mathrm{g} / \mathrm{ml}$ and $55.72 \mu \mathrm{g} / \mathrm{ml}$, respectively. The result pragmatically shows that AgNPs have profound super oxide activity against stable free radicals (Fig-2). 
Table 2: Super oxide radical scavenging activity of aqueous extract and AgNPs of S. wightii

\begin{tabular}{|l|l|l|l|}
\hline Concentration & Aqueous Extract & AgNPs & Rutin \\
\hline Control & $100 \pm 0$ & $100 \pm 0$ & $100 \pm 0$ \\
\hline $20 \mu \mathrm{g} / \mathrm{ml}$ & $0.681 \pm 0.001^{*}$ & $0.73 \pm 0.001^{*}$ & $0.741 \pm 0.001^{*}$ \\
& $(-7.30)$ & $(-7.48)$ & $(-16.99)$ \\
\hline $40 \mu \mathrm{g} / \mathrm{ml}$ & $0.547 \pm 0.003^{*}$ & $0.529 \pm 0.003^{*}$ & $0.601 \pm 0.005^{*}$ \\
& $(-25.58)$ & $(-32.91)$ & $(-32.58)$ \\
\hline $60 \mu \mathrm{g} / \mathrm{ml}$ & $0.464 \pm 0.002^{*}$ & $0.388 \pm 0.003^{*}$ & $0.405 \pm 0.002^{*}$ \\
& $(-36.87)$ & $(-50.82)$ & $(-54.59)$ \\
\hline $80 \mu \mathrm{g} / \mathrm{ml}$ & $0.378 \pm 0.001^{*}$ & $0.322 \pm 0.004^{*}$ & $0.322 \pm 0.002^{*}$ \\
& $(-48.62)$ & $(-59.19)$ & $(-63.94)$ \\
\hline $100 \mu \mathrm{g} / \mathrm{ml}$ & $0.299 \pm 0.002^{*}$ & $0.282 \pm 0.003^{*}$ & $0.282 \pm 0.002^{*}$ \\
& $(-59.27)$ & $(-64.31)$ & $(-68.42)$ \\
\hline $\mathbf{I C}_{\mathbf{5 0}}(\boldsymbol{\mu g} / \mathrm{ml})$ & 82.59 & 59.08 & 55.72 \\
\hline
\end{tabular}

Values are mean \pm S.E. of five individual observations.

Values in parentheses are per cent change over control.

- Denotes per cent decrease over control.

* Denotes that values are significant at $\mathrm{p}<0.05$.

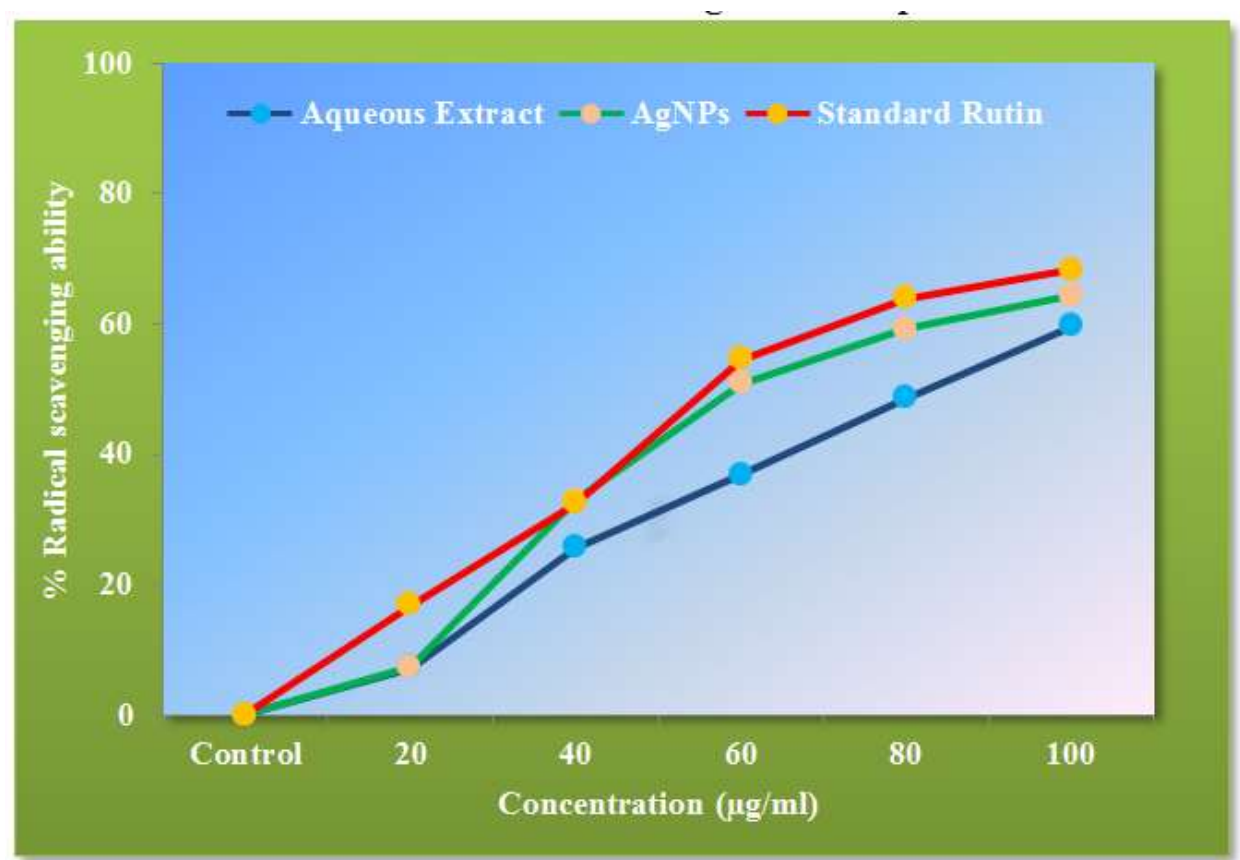

Fig-2: Super oxide radical scavenging activity of aqueous extract and AgNPs of $S$. wightii

\section{Metal Chelating Activity}

Metal chelating activity of aqueous extract and AgNPs of $S$. wightii and EDTA showed a per cent inhibition of $-12.61,-14.99$ and -20.37 , respectively at $200 \mu \mathrm{g} / \mathrm{ml}$ concentrations. As the concentration increased, the per cent inhibition also increased giving a value of $-61.11,-75.92$ and -79.19 in all the three samples at $1000 \mu \mathrm{g} / \mathrm{ml}$. All the values were found to be significant at 5\% level when analyzed by two-way ANOVA. The median inhibitory concentration $\left(\mathrm{IC}_{50}\right)$ of aqueous extract, AgNPs and standard EDTA was found to be $757.5 \mu \mathrm{g} / \mathrm{ml}, 634.22 \mu \mathrm{g} / \mathrm{ml}$ and $542.99 \mu \mathrm{g} / \mathrm{ml}$ respectively. The results altogether depicts that AgNPs have profound metal chelating activity against stable free radicals (Fig-3). 
Table-3: Metal chelating activity of aqueous extract and AgNPs of S. wightii

\begin{tabular}{|l|l|l|l|}
\hline Concentration & Aqueous Extract & AgNPs & Standard EDTA \\
\hline Control & $100 \pm 0$ & $100 \pm 0$ & $100 \pm 0$ \\
\hline $200 \mu \mathrm{g} / \mathrm{ml}$ & $0.330 \pm 0.006^{*}$ & $0.321 \pm 0.001^{*}$ & $0.301 \pm 0.001^{*}$ \\
& $(-12.61)$ & $(-14.99)$ & $(-20.37)$ \\
\hline $400 \mu \mathrm{g} / \mathrm{ml}$ & $0.278 \pm 0.002^{*}$ & $0.252 \pm 0.002^{*}$ & $0.238 \pm 0.004^{*}$ \\
& $(-26.45)$ & $(-33.24)$ & $(-36.95)$ \\
\hline $600 \mu \mathrm{g} / \mathrm{ml}$ & $0.005 \pm 0.002^{*}$ & $0.202 \pm 0.001^{*}$ & $0.169 \pm 0.004^{*}$ \\
& $(-41.18)$ & $(-46.56)$ & $(-55.21)$ \\
\hline $800 \mu \mathrm{g} / \mathrm{ml}$ & $0.18 \pm 0.002^{*}$ & $0.126 \pm 0.004^{*}$ & $0.099 \pm 0.002^{*}$ \\
& $(-52.38)$ & $(-66.67)$ & $(-73.72)$ \\
\hline $1000 \mu \mathrm{g} / \mathrm{ml}$ & $0.147 \pm 0.002^{*}$ & $0.091 \pm 0.002^{*}$ & $0.0787 \pm 0.002^{*}$ \\
& $(-61.11)$ & $(-75.92)$ & $(-79.19)$ \\
\hline $\mathbf{I C}_{\mathbf{5 0}}(\boldsymbol{\mu g} / \mathrm{ml})$ & 757.5 & 634.22 & 542.99 \\
\hline
\end{tabular}

Values are mean \pm S.E. of five individual observations.

Values in parentheses are per cent change over control.

- Denotes per cent decrease over control.

* Denotes that values are significant at $\mathrm{p}<0.05$.

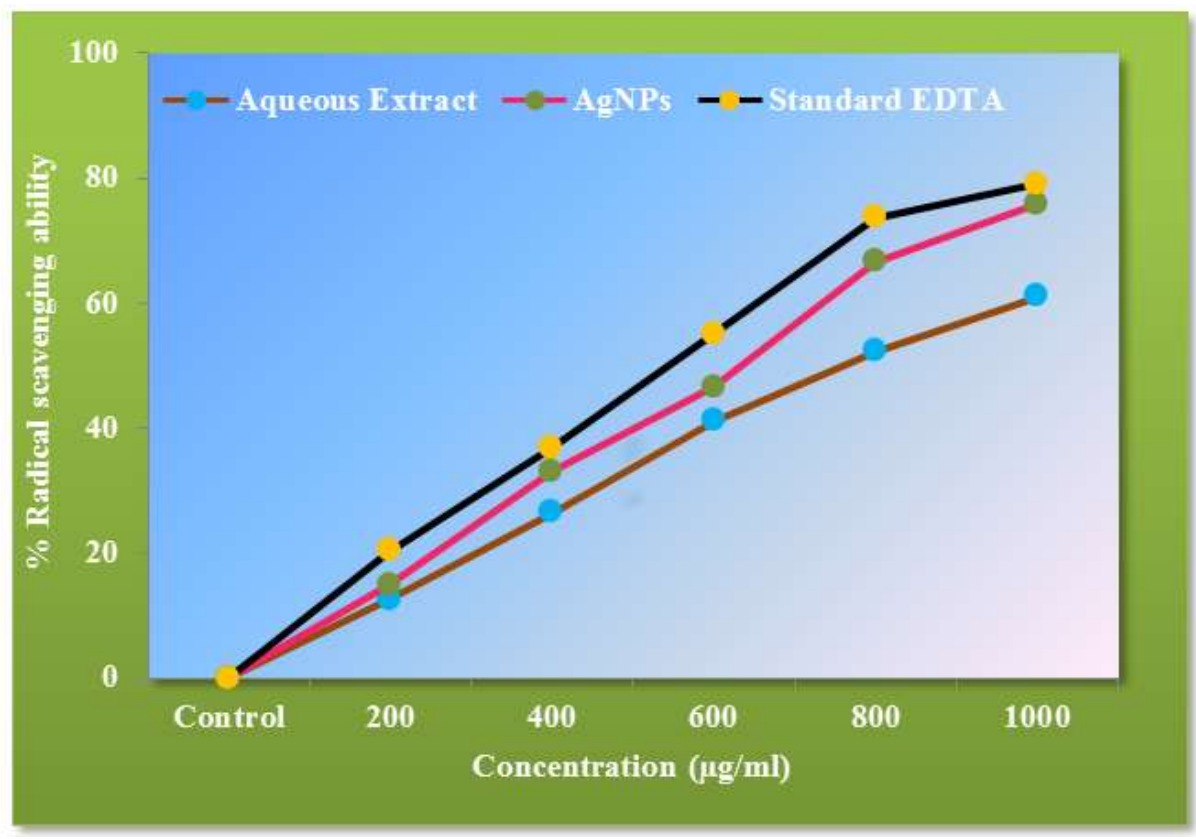

Fig-3: Metal chelating activity of aqueous extract and AgNPs of $S$. wightii

\section{Nitric Oxide Radical Scavenging Activity}

Nitric oxide radical scavenging activity of aqueous extract and AgNPs of S. wightii and BHT are presented in Table 4 . The per cent inhibition in nitric oxide radical scavenging increased as the concentration of the samples increased; the values being -7.61 to 52.78 in aqueous extract, -14.39 to -67.78 in AgNPs and -17.85 to -81.88 in standard BHT. The per cent inhibition was higher in AgNPs than that of the aqueous extract, thus revealing that AgNPs have profound antioxidant potential. Statistical analysis of the data by two-way ANOVA showed that all the values were significant at $5 \%$ level. The half maximal inhibitory concentration $\left(\mathrm{IC}_{50}\right)$ of aqueous extract, AgNPs and BHT was found to be $94.29 \mu \mathrm{g} / \mathrm{ml}, 69.05 \mu \mathrm{g} / \mathrm{ml}$ and $63.37 \mu \mathrm{g} / \mathrm{ml}$, respectively. This proves that AgNPs have profound nitric oxide radical scavenging activity against stable free radicals (Fig-4). 
Table-4: Nitric oxide scavenging activity of aqueous extract and AgNPs of S. wightii

\begin{tabular}{|l|l|l|l|}
\hline Concentration & Aqueous Extract & AgNPs & Standard BHT \\
\hline Control & $100 \pm 0$ & $100 \pm 0$ & $100 \pm 0$ \\
\hline $20 \mu \mathrm{g} / \mathrm{ml}$ & $0.648 \pm 0.002^{*}$ & $0.591 \pm 0.681^{*}$ & $0.707 \pm 0.002^{*}$ \\
& $(-7.61)$ & $(-14.39)$ & $(-17.85)$ \\
\hline $40 \mu \mathrm{g} / \mathrm{ml}$ & $0.579 \pm 0.001^{*}$ & $0.504 \pm 0.586^{*}$ & $0.604 \pm 0.006^{*}$ \\
& $(-17.36)$ & $(-26.91)$ & $(-29.89)$ \\
\hline $60 \mu \mathrm{g} / \mathrm{ml}$ & $0.459 \pm 0.004^{*}$ & $0.382 \pm 0.443^{*}$ & $0.45 \pm 0.003^{*}$ \\
& $(-34.57)$ & $(-44.68)$ & $(-47.73)$ \\
\hline $80 \mu \mathrm{g} / \mathrm{ml}$ & $0.399 \pm 0.001^{*}$ & $0.301 \pm 0.346^{*}$ & $0.334 \pm 0.002^{*}$ \\
& $(-43.03)$ & $(-56.42)$ & $(-61.21)$ \\
\hline $100 \mu \mathrm{g} / \mathrm{ml}$ & $0.331 \pm 0.003^{*}$ & $0.222 \pm 0.259^{*}$ & $0.156 \pm 0.003^{*}$ \\
& $(-52.78)$ & $(-67.78)$ & $(-81.88)$ \\
\hline $\mathbf{I C}_{\mathbf{5 0}}(\boldsymbol{\mu g} / \mathrm{ml})$ & 94.29 & 69.05 & 63.37 \\
\hline
\end{tabular}

Values are mean \pm S.E. of five individual observations.

Values in parentheses are per cent change over control.

- Denotes per cent decrease over control.

* Denotes that values are significant at $\mathrm{p}<0.05$.

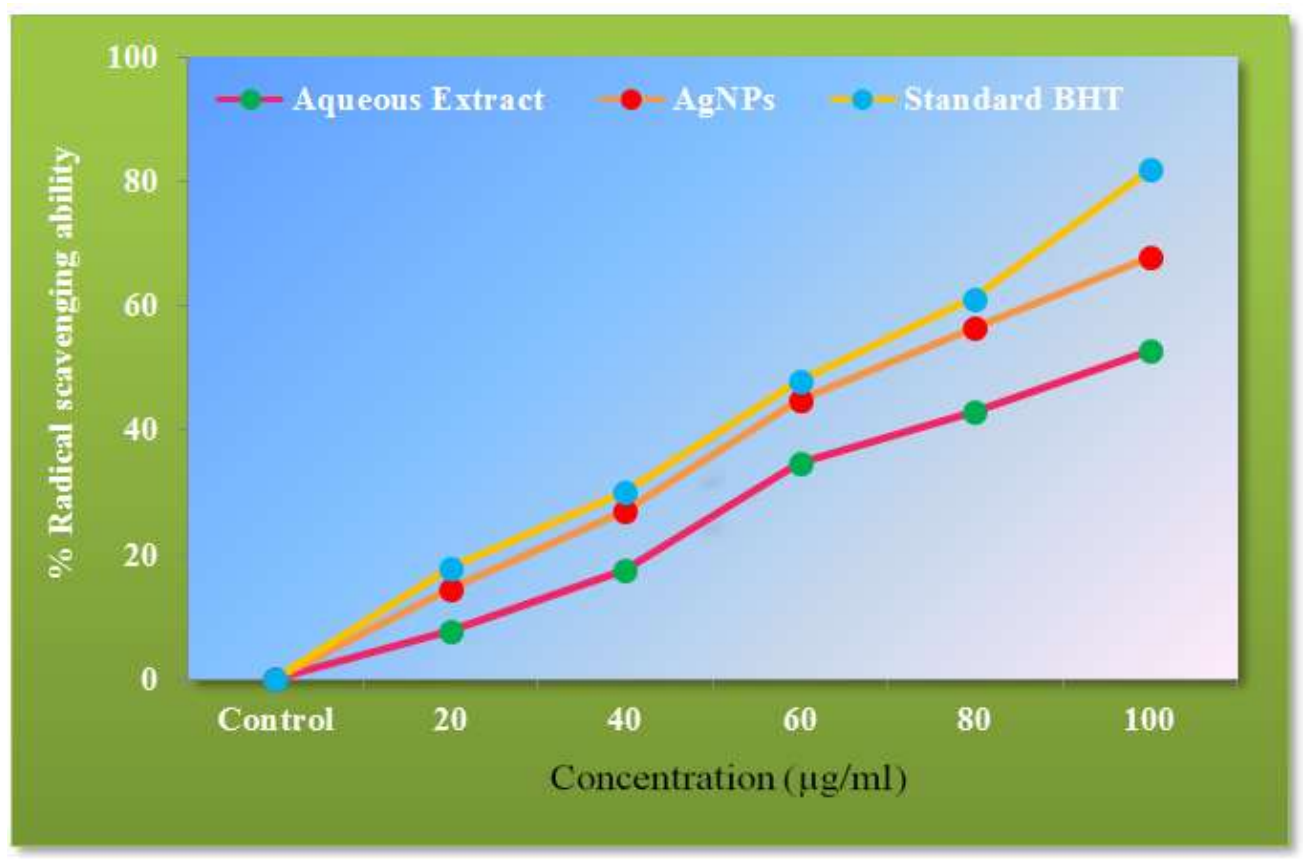

Fig-4: Nitric oxide scavenging activity of aqueous extract and AgNPs of $S$. wightii

\section{DiscuSSION}

According to Gupta and Abu-Ghannam [21], antioxidants are secondary metabolites that inhibit oxidation by transforming radicals into non-radicals by donating electrons and hydrogen, chelating transition metals and dissolving generated peroxidation compounds. The antioxidant compounds produced by plants include phenolic compounds such as flavonoids, cinnamic acid, benzoic acid, gallic acid, phlorotannins and quercetin. Among marine organisms, seaweeds represent one of the richest sources of antioxidants. $S$. wightii also shows a good amount of flavonoids in support and its antioxidant activity [22] indicating that this species is an ideal target for investigating the activity of the biomolecules present in $S$. wightii for various medical and industrial applications as opined by
Iswarya Devi et al., [23]. Radical scavenging effect of natural antioxidants could be evaluated using DPPH, a free radical donor under in vitro conditions as pointed out by Matsukawa et al., [24] and Jao and Ko [25].

Several authors have worked on antioxidant potential of seaweeds. Badrinathan et al., [26] evaluated the radical quenching activity of Sargassum myriocystum by DPPH assay, deoxy ribose radical scavenging activity, super oxide anion radical scavenging, reducing power and total antioxidant activity. It was presumed by the authors that from the phenolic contents, algal extracts have some other novel bio-molecules, which are responsible for $\mathrm{OH}$ - radical quenching activity. Similarly, Siti et al., [27] determined the antioxidant activity of brown algae Sargassum species like Sargassum polyceratium, 
Sargassum angustifolium, Sargassum filipendula, Sargassum hystrix and Sargassum cinereum. The antioxidant properties were evaluated by using 2,2Diphenyl-1-Picrylhydrzyl Radical Scavenging Activity (DPPH-RSA) and Ferrous Ion-Chelating (FIC) ability. The authors are of the opinion that the antioxidant property of Sargassum sp., was because of presence of high levels of phenolic and flavonoid content. In the present study also, the antioxidant property of $S$. wightii and its AgNPS might be due to the presence of phenolic and flavonoid content in $S$. wightii, thus finding support from the above authors.

Super oxide dismutase (SOD) is a metalloenzyme that catalyzes the dismutation of super oxide radical into hydrogen peroxide $\left(\mathrm{H}_{2} \mathrm{O}_{2}\right)$ and molecular oxygen $\left(\mathrm{O}_{2}\right)$ and consequently provides an important defense mechanism against super oxide radical toxicity as pointed out by Nishikimi et al., [28]. Liochev and Fridovich [29] have stated that super oxide anion radicals are formed in cellular oxidation reactions, and these radicals can result in the production of hydrogen peroxide and hydroxyl radicals through dismutation and other chemical reactions. Super oxide anions have a longer life time and can move over greater distances than other oxygen radicals; hence, they are more damaging. Therefore, the ability to scavenge super oxide anions is an important biological property for a therapeutic compound.

Singlet oxygen (O2-) is formed in almost all the viable and living cells through several metabolic reactions [30] and its effect can be magnified because it produces other types of free radicals and oxidizing agent that can induce cell damage, which leads to apoptosis or necrosis [31]. Antioxidants in algal extracts may inhibit both oxygen consumption and hydrogen peroxide formation. It has been shown that hydrogen peroxide together with reactive oxygen species (ROS) can damage several cellular components [32]. Hydroxyl radical has the highest 1-electron reduction potential $(2310 \mathrm{mV})$ and can react with anything in living organisms at the second order rate constants of 109 to $1010 \mathrm{~mol} / \mathrm{L} / \mathrm{s}$ [33], among various free radical compounds. It can react with lipids, polypeptides, saccharides, nucleotides and organic acids, especially thiamine and guanosine and thereby cause cell damage [34]. The results obtained by Badrinathan et al., [26] concluded that Sargassum myriocystum showed highest inhibition against $\mathrm{OH}-$ radicals than other reactive oxygen species, that apart from the phenolic contents, algal extracts have some other novel bio-molecules, which are responsible for $\mathrm{OH}-$ radical quenching activity.

Zhang et al., [35] in Sargassum graminifolium assessed antioxidant activities of SGP by determining its reducing power, its ability to scavenge superoxide radicals, and its activity in the 1,1-diphenyl-2- picrylhydrazyl (DPPH) assay. The scavenging of the DPPH free radical by antioxidants is due to their hydrogen-donating ability as opined by Bortolomeazzi et al., [36] and Fagali and Catal [37]. Moreover, Wang et al., [38] and Hassas-Roudsari et al., [39] have stated that reducing power assays are used to evaluate the capacity of natural antioxidants to donate an electron. Natural antioxidants are believed to break free-radical chain reactions by donating an electron or hydrogen atom to free radicals. Therefore, the reducing power of a compound is a significant indicator of its potential antioxidant activity. In the present case also, the DPPH radical scavenging activity might be due to hydrogendonating ability of the $S$. wightii and its ability to break free-radical chain reactions by donating an electron or hydrogen atom to free radicals.

Govindaraju et al., [40] determined antioxidant activity of the biosynthesized AgNPs and analyzed using ultrasonic-induced lipid peroxidation in the liposomal membrane of Sargassum vulgare. The study revealed that the biosynthesized AgNPs exhibited the antioxidant activity in a dose-dependent manner. This is in agreement with the previous reports on the antioxidant property of the biosynthesized AgNPs by Veerapandian et al., [41]. It is well known that the surface chemistry of the NP plays a vital role in their cellular responses as stated by Krishnamoorthy et al., [42]. Previous study by Jain et al., also demonstrated that AgNPs treatment reduce the lipid peroxidation and increase the glutathione and superoxide dismutase levels in primary fibroblast cells. However, the generation of free radicals by chemically synthesized AgNPs has also been reported by Vankayala et al., [43]. These divisive results arise from the synthesis methods and the nature of reducing agent used for the preparation of AgNPs.

Antioxidant property of biosynthesized AgNPs was due to the following reasons: alginate, being a natural antioxidant material, acted as a reducing and stabilizing agent in the biosynthesis, resulting in the surface modification of AgNPs and the fact was supported by Zubia et al., [44], Kanagalakshmi et al., [45], Premanathan et al., [46], Veerapandian et al., [41] and Govindaraju et al., [40]. The similar type of observations were seen in the biosynthesized AgNPs using Trichoderma viride by Fayaz et al., [47] and Brevibacterium casei by Kalishwaralal et al., [48]. Hence, the surface modification of AgNPs during biosynthesis plays a vital role in their intracellular response. In conclusion, the biosynthesized AgNPs inhibited the lipid peroxidation-mediated reactive oxygen species generation thus preventing the irradiation-related carcinogenesis.

In the present study, the antioxidant activity was assessed by DPPH, super oxide anion radical scavenging activity, metal chelating activity and nitric 
oxide radical scavenging activity. The reports of the above authors support the observations of the present study. In our study also, a similar mechanism of surface modification of AgNPs leading to inhibition of lipid peroxidation-mediated reactive oxygen species generation, thus preventing the irradiation-related carcinogenesis might have operated leading to the inhibition of DPPH, super oxide radical scavenging, metal chelating and nitric oxide radical scavenging activity in aqueous and AgNPs of $S$. wightii. Moreover, the AgNPs might have endocytosed into the cells and damaged the DNA leading to apoptosis.

\section{CONCLUSION}

In the present study, the aqueous extract and its synthesized AgNPs showed high antioxidant activity to the best of our knowledge. Hence, green synthesized AgNPs of $S$. wightii can be used as a potential therapeutic drug for various diseases due to its bioactive properties.

\section{REFERENCES}

1. Song, J. Y., \& Kim, B. S. (2008). Biological synthesis of bimetallic $\mathrm{Au} / \mathrm{Ag}$ nanoparticles using Persimmon (Diopyros kaki) leaf extract. Korean Journal of Chemical Engineering, 25(4), 808-811.

2. Ashok, K., Sivakumari, K., \& Rajesh, S. (2018). Achyranthes aspera mediated green synthesis of silver nanoparticles. Indo American Journal of Pharmaceutical Sciences, 5(1), 64-73.

3. Kohl, Y., Kaiser, C., Bost, W., Stracke, F., Fournelle, M., Wischke, C., .. \& Lemor, R. (2011). Preparation and biological evaluation of multifunctional PLGA-nanoparticles designed for photoacoustic imaging. Nanomedicine: Nanotechnology, Biology and Medicine, 7(2), 228237.

4. Meng, H., Liong, M., Xia, T., Li, Z., Ji, Z., Zink, J. I., \& Nel, A. E. (2010). Engineered design of mesoporous silica nanoparticles to deliver doxorubicin and P-glycoprotein siRNA to overcome drug resistance in a cancer cell line. ACS nano, 4(8), 4539-4550.

5. Godin, B., Sakamoto, J. H., Serda, R. E., Grattoni, A., Bouamrani, A., \& Ferrari, M. (2010). Emerging applications of nanomedicine for the diagnosis and treatment of cardiovascular diseases. Trends in pharmacological sciences, 31(5), 199-205.

6. Tian, J., Wong, K. K., Ho, C. M., Lok, C. N., Yu, W. Y., Che, C. M., ... \& Tam, P. K. (2007). Topical delivery of silver nanoparticles promotes wound healing. ChemMedChem, 2(1), 129-136.

7. Jayaprakash, P., Sivakumari, K., Ashok, K., \& Rajesh, S. (2018). In silico molecular docking of alginic acid and fucoidan compound present in $S$. wightii against apoptotic proteins (caspase-3, caspase- 9 and $\beta$-actin). IJBPAS, 7(8), 1551-1565.
8. Flora Priyadarshini, J., Sivakumari, K., Rajesh, S., Ashok, K., \& Jayaprakash, P. (2020). In vitro antioxidant, anticancer and apoptotic potential of green synthesized silver nanoparticles from propolis against human hepatocellular carcinoma (HepG-2) cells. Alochana Chakra J. 9(5), 801820.

9. Rangari, V. K., Mohammad, G. M., Jeelani, S., Hundley, A., Vig, K., \& Singh, S. R. (2010). Synthesis of Ag/CNT hybrid NPs and fabrication of their nylon-6 polymer nanocomposite fibers for antimicrobial applications. Nanotech, 21(9): 95102

10. Priyadarshini, J. F., Sivakumari, K., Selvaraj, R., Ashok, K., Jayaprakash, P., \& Rajesh, S. (2018). Green synthesis of silver nanoparticles from propolis. Res J Life Sci Bioinform Pharm Chem Sci, 4, 23-36.

11. Majumder, I., Paul, S., \& Kundu, R. (2015). Anticancerous and Anti-tumourous activity of algae - A review. IJIPSR, 3(2): 72-89.

12. Sobha, V., Santhosh, S., Chitra, G., Hashim, K. A., \& Valsalakumar, E. (2009). Alginic acid in different parts of Sargassum wightii and Padina tetrastromatica. Acad Rev, 16, 107-115.

13. Rout, S., \& Kumar, A. (2015). A review on the potentiality of marine seaweeds as a medicinal source. World journal of pharmacy and pharmaceutical sciences, 4(10):458-476.

14. Song, J. Y., \& Kim, B. S. (2009). Rapid biological synthesis of silver nanoparticles using plant leaf extracts. Bioprocess and biosystems engineering, 32(1), 79-84.

15. Jayaprakash, P., Sivakumari, K., Ashok, K., Rajesh, S., Prabhu, D., \& Chandrasekar, D. (2017). Anticancer potential of green synthesized silver nanoparticles of Sargassum wightii againts human prostate cancer (PC-3) cell line. Ejpmr, 4(3), 275-287.

16. McCune, L. M., \& Johns, T. (2002). Antioxidant activity in medicinal plants associated with the symptoms of diabetes mellitus used by the indigenous peoples of the North American boreal forest. Journal of Ethnopharmacology,82(2-3), 197-205.

17. Jing, T. Y., \& Zhao, X. Y. (1995). The improved pyrogallol method by using terminating agent for superoxide dismutase measurement. Prog. Biochem. Biophys, 22(1), 84-86.

18. Soler-Rivas, C., Espín, J. C., \& Wichers, H. J. (2000). An easy and fast test to compare total free radical scavenger capacity of foodstuffs. Phytochemical Analysis: An International Journal of Plant Chemical and Biochemical Techniques, 11(5), 330-338.

19. Green, L. C., Wagner, D. A., Glogowski, J., Skipper, P. L., Wishnok, J. S., \& Tannenbaum, S. R. (1982). Analysis of nitrate, nitrite, and [15N] 
nitrate in biological fluids. Analytical biochemistry, 126(1), 131-138.

20. Rajesh, S., Sivakumari, K., Ashok, K., \& Abitha, A. R. (2016). Anti-cancer activity of Cardiospermum halicacabum Linn. leaf extracts against hepatocellular carcinoma cell line (HepG2). World J Pharm Pharm Sci, 5(3), 1133-1154.

21. Gupta, S., \& Abu-Ghannam, N. (2011). Recent developments in the application of seaweeds or seaweed extracts as a means for enhancing the safety and quality attributes of foods. Innovative Food Science \& Emerging Technologies, 12(4), 600-609.

22. Meenakshi, S., Gnanambigai, D. M., Mozhi, S. T., Arumugam, M., \& Balasubramanian, T. (2009). Total flavanoid and in vitro antioxidant activity of two seaweeds of Rameshwaram coast. Global $J$ Pharmacol, 3(2), 59-62.

23. Devi, J. A. I., Balan, G. S., \& Periyanayagam, K. (2013). Pharmacognostical study and phytochemical evaluation of brown seaweed Sargassum wightii. Journal of Coastal Life Medicine, 1(3), 199-204.

24. Matsukawa, R., Dubinsky, Z., Kishimoto, E., Masaki, K., Masuda, Y., Takeuchi, T., ... \& Karube, I. (1997). A comparison of screening methods for antioxidant activity in seaweeds. Journal of Applied Phycology, 9(1), 29.

25. Jao, C. L., \& Ko, W. C. (2002). 1, 1-Diphenyl-2picrylhydrazyl (DPPH) radical scavenging by protein hydrolyzates from tuna cooking juice. Fisheries Science, 68(2), 430-435.

26. Badrinathan, S., Shiju, T. M., Christa, A. S. S., Arya, R., \& Pragasam, V. (2012). Purification and structural characterization of sulfated polysaccharide from Sargassum myriocystum and its efficacy in scavenging free radicals. Indian journal of pharmaceutical sciences, 74(6), 549555.

27. Budhiyanti, S. A., Raharjo, S., Marseno, D. W., \& Lelana, I. Y. (2012). Antioxidant activity of brown algae Sargassum species extracts from the coastline of java island. American Journal of Agricultural and Biological Science. 7(3): 337346.

28. Nishikimi, M., Rao, N. A., \& Yagi, K. (1972). The occurrence of superoxide anion in the reaction of reduced phenazine methosulfate and molecular oxygen. Biochemical and biophysical research communications, 46(2), 849-854.

29. Liochev, S. I., \& Fridovich, I. (1999). The relative importance of $\mathrm{HO}^{*}$ and ONOO-in mediating the toxicity of $\mathrm{O}^{*}$-. Free radical biology \& medicine, 26(5-6), 777-778.

30. Fridovich, I. (1986). Superoxide dismutases. $A d v$ Enzymol Relat Areas Mol Biol, 58(6), 61-97.

31. Liu, F., \& Ng, T. B. (2000). Antioxidative and free radical scavenging activities of selected medicinal herbs. Life sciences, 66(8), 725-735.
32. Burdon, R. H. (1995). Superoxide and hydrogen peroxide in relation to mammalian cell proliferation. Free Radical Biology and Medicine, 18(4), 775-794.

33. Korycka-Dahl, M., \& Richardson, T. (1978). Photogeneration of superoxide anion in serum of bovine milk and in model systems containing riboflavin and amino acids. Journal of Dairy Science, 61(4), 400-407.

34. Ashok, B. T., \& Ali, R. (1999). The aging paradox: free radical theory of aging. Experimental gerontology, 34(3), 293-303.

35. Zhang, C. Y., Wu, W. H., Wang, J., \& Lan, M. B. (2012). Antioxidant properties of polysaccharide from the brown seaweed Sargassum graminifolium (Turn.), and its effects on calcium oxalate crystallization. Marine drugs, 10(1), 119130.

36. Bortolomeazzi, R., Sebastianutto, N., Toniolo, R., \& Pizzariello, A. (2007). Comparative evaluation of the antioxidant capacity of smoke flavouring phenols by crocin bleaching inhibition, DPPH radical scavenging and oxidation potential. Food Chemistry, 100(4), 1481-1489.

37. Fagali, N., \& Catalá, A. (2008). Antioxidant activity of conjugated linoleic acid isomers, linoleic acid and its methyl ester determined by photoemission and DPPH techniques. Biophysical Chemistry, 137(1), 56-62.

38. Wang, H., Gao, X. D., Zhou, G. C., Cai, L., \& Yao, W. B. (2008). In vitro and in vivo antioxidant activity of aqueous extract from Choerospondias axillaris fruit. Food Chemistry, 106(3), 888-895.

39. Hassas-Roudsari, M., Chang, P. R., Pegg, R. B., \& Tyler, R. T. (2009). Antioxidant capacity of bioactives extracted from canola meal by subcritical water, ethanolic and hot water extraction. Food Chemistry, 114(2), 717-726.

40. Govindaraju, K., Krishnamoorthy, K., Alsagaby, S. A., Singaravelu, G., \& Premanathan, M. (2015). Green synthesis of silver nanoparticles for selective toxicity towards cancer cells. IET nanobiotechnology, 9(6), 325-330.

41. Veeraapandian, S., Sawant, S. N., \& Doble, M. (2012). Antibacterial and antioxidant activity of protein capped silver and gold nanoparticles synthesized with Escherichia coli. Journal of biomedical nanotechnology, 8(1), 140-148.

42. Krishnamoorthy, K., Moon, J. Y., Hyun, H. B., Cho, S. K., \& Kim, S. J. (2012). Mechanistic investigation on the toxicity of $\mathrm{MgO}$ nanoparticles toward cancer cells. Journal of materials chemistry, 22(47), 24610-24617.

43. Vankayala, R., Kuo, C. L., Sagadevan, A., Chen, P. H., Chiang, C. S., \& Hwang, K. C. (2013). Morphology dependent photosensitization and formation of singlet oxygen ( $1 \Delta \mathrm{g})$ by gold and silver nanoparticles and its application in cancer 
Jayaprakash Ponmani et al., Saudi J Med Pharm Sci, August, 2020; 6(8): 516-525

treatment. Journal of Materials Chemistry $B, 1(35), 4379-4387$.

44. Zubia, M., Payri, C., \& Deslandes, E. (2008). Alginate, mannitol, phenolic compounds and biological activities of two range-extending brown algae, Sargassum mangarevense and Turbinaria ornata (Phaeophyta: Fucales), from Tahiti (French Polynesia). Journal of Applied Phycology, 20(6), 1033-1043.

45. Kanagalakshmi, K., Premanathan, M., Priyanka, R., Hemalatha, B., \& Vanangamudi, A. (2010). Synthesis, anticancer and antioxidant activities of 7-methoxyisoflavanone and 2, 3diarylchromanones. European journal of medicinal chemistry, 45(6), 2447-2452.

46. Premanathan, M., Karthikeyan, K., Jeyasubramanian, K., \& Manivannan, G. (2011). Selective toxicity of $\mathrm{ZnO}$ nanoparticles toward
Gram-positive bacteria and cancer cells by apoptosis through lipid peroxidation. Nanomedicine: Nanotechnology, Biology and Medicine, 7(2), 184-192.

47. Fayaz, A. M., Balaji, K., Girilal, M., Yadav, R., Kalaichelvan, P. T., \& Venketesan, R. (2010). Biogenic synthesis of silver nanoparticles and their synergistic effect with antibiotics: a study against gram-positive and gram-negative bacteria. Nanomedicine: Nanotechnology, Biology and Medicine, 6(1), 103-109.

48. Kalishwaralal, K., Deepak, V., Pandian, S. R. K., Kottaisamy, M., BarathManiKanth, S., Kartikeyan, B., \& Gurunathan, S. (2010). Biosynthesis of silver and gold nanoparticles using Brevibacterium casei. Colloids and surfaces B: Biointerfaces, 77(2), 257-262. 